\title{
Small intestine perforation after colonoscopy: rare complication in patients with previous abdominal surgery
}

A 69-year-old woman with history of previous abdominal surgery (myomectomy and right hemicolectomy for an obstructive non-neoplastic inflammatory mass of uncertain etiology) presented with abdominal subocclusive episodes and weight loss. Blood analysis, tumor markers carcinoembryonic antigen (CEA) and CA 19.9, and abdominal computed tomography (CT) were normal. The patient underwent colonoscopy under conscious sedation and the surgical anastomosis was accessed without difficulty. No pathology was detected and no therapeutic measures were undertaken during the procedure. Two hours later, the patient had severe abdominal pain with peritonism and leukocytosis $\left(14.5 \times 10^{9} / \mathrm{L}\right)$. An abdominal film revealed pneumoperitoneum, so the surgeon proceeded with an urgent laparotomy. Multiple peritoneal adhesions were found, some of which were adherent to both small intestine loops and the sigmoid colon. The colon was intact, but on removing the adhesions between the small intestine loops, a perforation was found in the mid-ileum. The perforated segment was resected and a primary anastomosis carried out. The patient was discharged 3 weeks after the surgery.

Colonic perforation is a well-known complication of colonoscopy [1,2]. However, perforation of the small intestine is more rare. To our knowledge this is the sixth published case of this complication, with the affected segment always being the ileum ( Table 1 ).

In two of the cases, polypectomy was carried out, during which electric current may have been transmitted to a small intestine loop adjacent to the colon, perforating it $[3,4]$. In another case the perfora-

Table 1 Main characteristics of published cases of small intestinal perforation after colonoscopy.

\begin{tabular}{llll} 
Reference & Endoscopic therapy & Time of perforation & Previous ileal \\
Razzak et al. [6] & No & Early & No \\
\hline Erdman et al. [4] & Polypectomy & Early & No \\
\hline Nemeh et al. [7] & No & Early & No \\
\hline Chau et al. [5] & No & Late & Chronic ischemia \\
\hline Lambert et al. [3] & Polypectomy & Early & No \\
\hline Teruel et al. & No & Early & No
\end{tabular}

tion occurred 7 days after the colonoscopy in an ileal segment already affected by chronic ischemia [5]. In the remaining two cases published previously, the perforation occurred after nontherapeutic colonoscopy in patients with major postsurgical adhesions [6,7], a situation similar to our case. The perforation may be the consequence of a tear caused by traction forces transmitted from the sigmoid colon to the adhesions between the small intestine loops when the colonoscope is introduced. This infrequent complication should be kept in mind in patients with previous open abdominal surgery.

\section{Endoscopy_UCTN_Code_CPL_1AJ_2AB}

\section{Teruel, X. A. García, A. Ledo, J. Graus, L. R. del Árbol}

Department of Gastroenterology, Hospital Ramón y Cajal, Madrid, Spain

\section{References}

1 Lüning TH, Keemers-Gels ME, Barendregt WB et al. Colonoscopic perforations: a review of 30366 patients. Surg Endosc 2007; 21: 994-997

2 Rathgaber SW, Wick TM. Colonoscopy completion and complication rates in a community gastroenterology practice. Gastrointest Endosc 2006; 64: 556-562
3 Lambert A, Nguyen SQ Byrn JC et al. Smallbowel perforation after colonoscopy. Gastrointest Endosc 2007; 65: $352-353$

4 Erdman LH, Boggs HW Jr, Slagle GW. Electric ileal perforation: an unusual complication of colonoscopy. Dis Colon Rectum 1979; 22: $501-502$

5 Chau TN, Ng C, Lau LK et al. Delayed midileal perforation secondary to acute-onchronic ischaemia after a diagnostic colonoscopy. Scand J Gastroenterol 1998; 33: $1002-1004$

6 Razzak IA, Millan J, Schuster MM. Pneumatic ileal perforation: an unusual complication of colonoscopy. Gastroenterology 1976; 2: 268-271

7 Nemeh HW, Ranzinger MR, Dutro JA. Midileal perforation secondary to colonoscopy. Am Surg 1994; 60: 228 - 229

Bibliography

DOI $10.1055 / \mathrm{s}-0029-1214599$

Endoscopy 2009; 41: E116

(c) Georg Thieme Verlag KG Stuttgart · New York . ISSN 0013-726X

Corresponding author

\section{Teruel}

Gastroenterology Department

Hospital Ramón y Cajal

Ctra. de Colmenar Viejo, Km 9,100

28034 Madrid

Spain

Fax: +34-913-368354

cteruelvegazo@yahoo.es 